
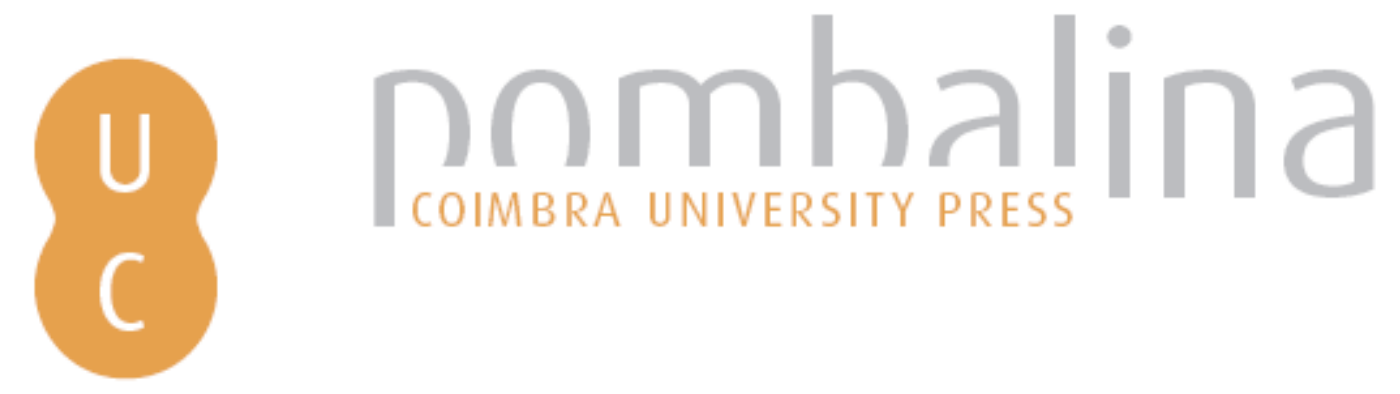

\title{
Saúde e risco ambiental: o caso dos usuários de fogão a lenha no estado do Ceará, região Nordeste do Brasil
}

\author{
Autor(es): $\quad$ Carvalho, Ricardo Luis Teles de; Silva, Adeildo Cabral da; Lombardo, \\ Magda Adelaide \\ Publicado por: Imprensa da Universidade de Coimbra; RISCOS - Associação \\ Portuguesa de Riscos, Prevenção e Segurança \\ URL \\ persistente: \\ URI:http://hdl.handle.net/10316.2/34889 \\ DOI: \\ DOI:http://dx.doi.org/10.14195/978-989-96253-3-4_88 \\ Accessed : $\quad$ 26-Apr-2023 03:30:35
}

A navegação consulta e descarregamento dos títulos inseridos nas Bibliotecas Digitais UC Digitalis, UC Pombalina e UC Impactum, pressupõem a aceitação plena e sem reservas dos Termos e Condições de Uso destas Bibliotecas Digitais, disponíveis em https://digitalis.uc.pt/pt-pt/termos.

Conforme exposto nos referidos Termos e Condições de Uso, o descarregamento de títulos de acesso restrito requer uma licença válida de autorização devendo o utilizador aceder ao(s) documento(s) a partir de um endereço de IP da instituição detentora da supramencionada licença.

Ao utilizador é apenas permitido o descarregamento para uso pessoal, pelo que o emprego do(s) título(s) descarregado(s) para outro fim, designadamente comercial, carece de autorização do respetivo autor ou editor da obra.

Na medida em que todas as obras da UC Digitalis se encontram protegidas pelo Código do Direito de Autor e Direitos Conexos e demais legislação aplicável, toda a cópia, parcial ou total, deste documento, nos casos em que é legalmente admitida, deverá conter ou fazer-se acompanhar por este aviso.

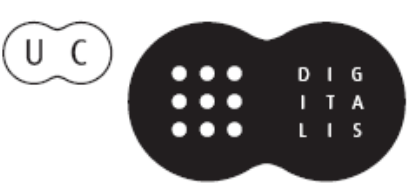



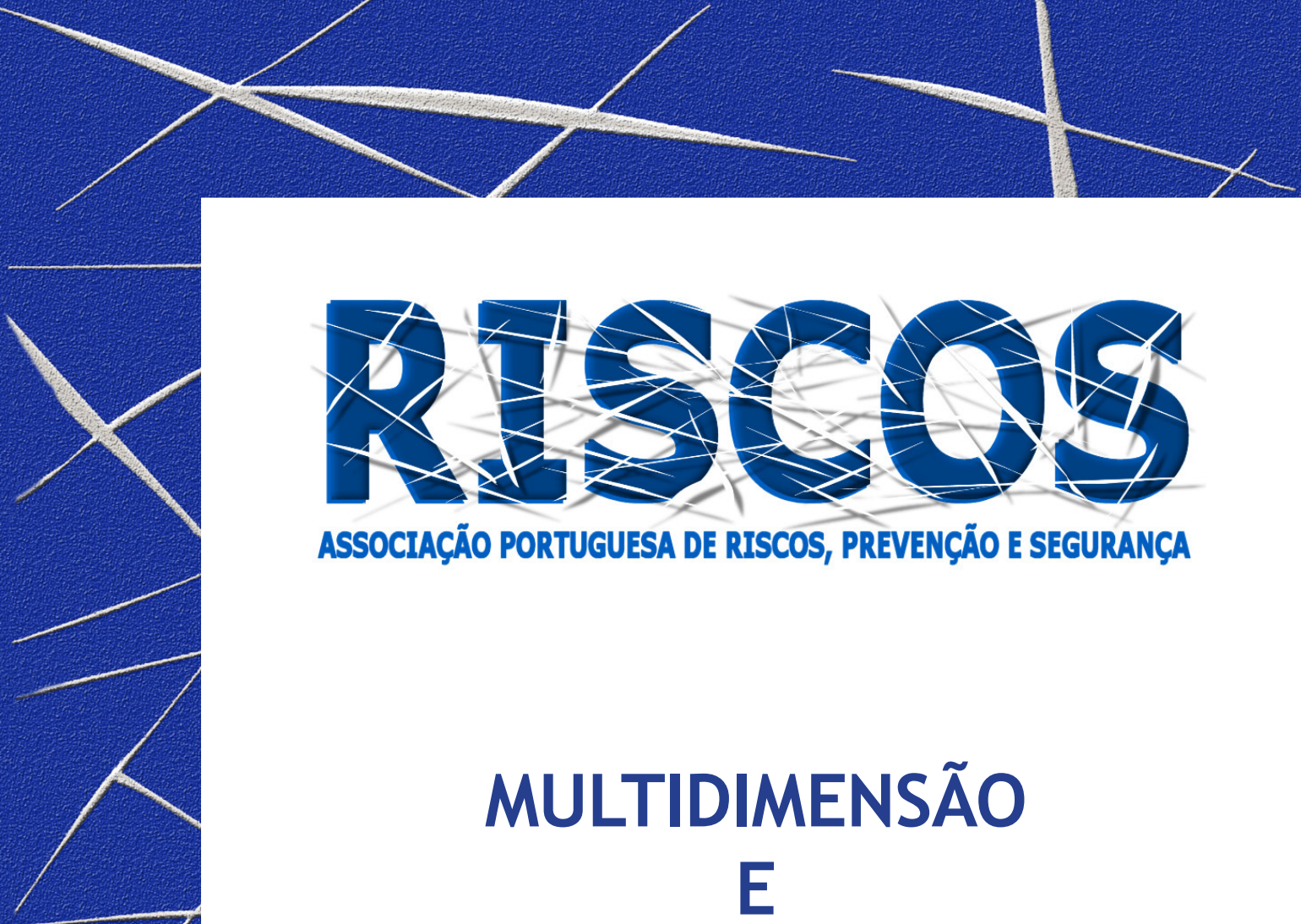

ASSOCIAÇÃO PORTUGUESA DE RISCOS, PREVENCCÃO E SEGURANÇA

MULTIDIMENSÃO

E
TERRITÓRIOS DE RISCO

III Congresso Internacional

I Simpósio Ibero-Americano

VIII Encontro Nacional de Riscos

Guimarães

2014 


\title{
SAÚDE E RISCO AMBIENTAL: O CASO DOS USUÁRIOS DE FOGÃO A LENHA NO ESTADO DO CEARÁ, REGIÃO NORDESTE DO BRASIL
}

\author{
Ricardo Luis Teles de Carvalho \\ Doctoral Programme in Civil Engineering, Aalborg University, Copenhagen, Denmark \\ rlc@sbi.aau.dk \\ Adeildo Cabral da Silva \\ Departamento de Construção Civil, Instituto Federal de Educação, Ciência e Tecnologia do Ceará, Fortaleza, Brasil \\ cabral@ifce.edu.br \\ Magda Adelaide Lombardo \\ Instituto de Geociências e Ciências Exatas, UNESP, Rio Claro, Brasil \\ lombardo@rc.unesp.br
}

\begin{abstract}
RESUMO
Segundo a Organização Mundial de Saúde (OMS), estudos ambientais e epidemiológicos em comunidades expostas a fumaça proveniente da queima de biomassa em ambientes internos, indicaram relação consistente entre a exposição e aumento de doenças respiratórias e, conseguentemente baixa qualidade de vida da população exposta. A reduzida eficiência dos fogões tradicionais de cozinha se constitui um problema ambiental para famílias de baixa renda do Ceará. A pesquisa objetivou uma análise relacionada ao uso dos novos (ecoeficientes) e tradicionais fogões em três municípios do Estado (Limoeiro do Norte, Horizonte e Maranguape) em habitações predominantemente rurais. No primeiro estudo de caso, em uma comunidade com 75 famílias abrangidas pelo projeto, foi realizada aplicação de questionários e medições de conforto ambiental no local. Concluiu-se que $13 \%$ do consumo de energia diz respeito ao gás butano e $87 \%$ está relacionado ao uso de lenha, sendo que $20 \%$ das famílias sentem desconforto provocado pela fumaça e aumento da temperatura interior causado pelos fogões melhorados. No interior de uma habitação, onde se utiliza o fogão (ecoeficiente), a concentração máxima de $\mathrm{CO}_{2}$ foi $922 \mathrm{ppm}$ e a temperatura média do ar $28^{\circ} \mathrm{C}$, com baixos valores de umidade relativa média do ar, de $28 \%$. 0 trabalho de monitoramento do conforto ambiental nos três municípios foi finalizado, e os dados serão objeto do trabalho completo.
\end{abstract}

Palavras-chave: biomassa, impacto ambiental, saúde pública.

\section{Introdução}

Os fogões a lenha são uma das tecnologias de fornecimento de energia mais ancestrais e populares do mundo, sendo que 3 bilhões de pessoas no mundo utiliza fogões a biomassa nas suas actividades de cozinha ou para o aquecimento doméstico (SIMON, 2011; UNDP 2009). Os problemas de saúde ocupacional e ambientais têm vindo a aumentar devido à combustão interior de biomassa e é reconhecido que o número de pessoas afectadas em 2030 possa ultrapassar os 200 milhões.

Atualmente, o uso de fogões a biomassa é a quarta maior causa de morte em países em desenvolvimento, sendo que as mulheres e crianças são os grupos mais expostos aos problemas causados pela combustão doméstica (CIAP, 2012).

$\mathrm{Na}$ Amércia Latina, os fogões de cozinha são bastante populares em habitações rurais, onde predominam as construções tradicionais e onde existe potencial para o desenvolvimento de culturas de agrofloresta (MAIA, 2008).

Apesar da instalação recente de 23000 unidades de fogões eco-eficientes em habitações (26500 famílias) nos estados do Ceará e Amazonas, ainda não foi efectuado estudo consistente sobre os impactos da sua utilização no clima interior das habitações rurais (IDER, 2008); sendo assim 
o objetivo geral desse projeto foi analisar o uso dos novos (ecoeficientes) e tradicionais fogões em três municípios do Estado (Limoeiro do Norte, Horizonte e Maranguape) em habitações predominantemente rurais em relação aos impactos socioambientais.

\section{Áreas de estudo}

Como estudo de caso específico para essa publicação seleccionou-se uma pequena comunidade rural de baixa renda, localizada na região semi-árida do baixo Jaguaribe (Litoral Leste do estado do Ceará-Brasil) no Município de Limoeiro do Norte. Segundo o IDER (2012), neste município foram instalados 477 novos fogões afectando 11 comunidades onde residem 2936 famílias. o trabalho de coleta de dados foi executado na comunidade do $\mathrm{Km60}$, onde foram instalados mais fogões ecoeficientes e uma das mais isoladas do referido município. Nesta localidade habitam 174 famílias onde foram instalados 75 fogões a lenha ecoeficientes.

A comunidade do Km60 encontra-se afastada do centro da cidade de Limoeiro do Norte e é uma região com disponibilidade de lenha para uso em fogões de cozinha, tendo sido esse um dos critérios relevantes na escolha da aplicação do estudo de caso.

\section{Estudo de caso no interior Ceará}

Foi realizado um estudo caso em tres Municípios, através da aplicação de questionários em habitações construídas em alvenaria (telha cerâmica e piso de cimento queimado), com o objectivo de efectuar um levantamento sobre a percepção dos seus habitantes acerca do impacto da combustão de lenha em fogões ecoeficientes no conforto ambiental interno, com ênfase nas problemáticas das perdas de energia térmica por sobreaquecimento. Foi efetuado um levantamento sobre o estado actual de uso dos fogões e padrões típicos de consumo de energia nas habitações unifamiliares. Também foram elaboradas questões relacionadas aos impactos do uso dos fogões ecoeficientes na qualidade do ar interior (emissão de gases de combustão) e os problemas de saúde associados como a asma e alergias.

O estudo de campo e respectivas entrevistas decorreram durante o mês de Agosto/2012, tendo contado com a colaboração dos alunos participantes no curso Gestão de Energia e Qualidade do Ar - Programa de Pós-graduação em Tecnologia e Gestão Ambiental (PPGTGA) do IFCE.

\section{Resultados}

No primeiro estudo de caso com o tópico: estudo compreensivo do conforto ambiental em habitações rurais do Ceará, Carvalho, R.L.T. Silva, A. C. Santos, P.G.L. e Tarelho, A. L. C. publicaram na Revista Geonorte (CARVALHO et al., 2012) resultados prelimires do trabalho de campo desenvolvido na localidade do Km 60. Apresenta-se aqui uma análise dos resultados dos dados coletados em campo pelos alunos do PPGTGA do IFCE. em conjunto com informações obtidas por meio de sensores e de monitoramento automático de dados.

Segundo Carvalho et al. (2012) sobre a saúde ocupacional e qualidade do ar interior foi identificado que, das habitações em estudo, $47 \%$ das famílias revelaram ter problemas de saúde e 40\% das famílias revelou existirem doenças ou sintomas de asma e/ou alergias nas suas casas. Cinco famílias apresentaram queixas sobre desconforto ambiental provocado pela utilização dos fogões a lenha, sendo 3 das quais relacionadas com a operação de fogões ecoeficientes ( $20 \%$ das famílias envolvidas neste estudo).

Na sessão de monitoramento realizada em uma das habitação resultou que a temperatura do ar interna, junto ao fogão a lenha ecoeficiente, variou entre $34,2{ }^{\circ} \mathrm{C}$ (início da tarde) e $32,7^{\circ} \mathrm{C}$ 
(final da tarde), enquanto a umidade relativa no mesmo ponto variou entre $29,7 \%$ (início da tarde) e $28,0 \%$ (final da tarde). A temperatura do ar no exterior variou entre os $37,8^{\circ} \mathrm{C}$ (início da tarde) e os $35,2^{\circ} \mathrm{C}$ (final da tarde).

A concentração de $\mathrm{CO}_{2}$ variou entre os 922 ppm (meio da tarde) e 908 ppm (final da tarde). 0 pico de concentração $\mathrm{CO}_{2}$ decocorreu pelas $16 \mathrm{~h} 02$, aquando do manuseamento da câmara de combustão para demonstração do funcionamento do processo de combustão de lenha no fogão ecoeficiente. 0 ponto de amostragem junto ao fogão ecoeficiente encontrava-se localizado num pátio anexo à casa, bem ventilado pelas correntes de ar que atravessam a mesma, ventilação natural promovida pela abertura de portas e janelas da habitação.

Na continuidade da análise sobre o uso dos fogoes no estado do Ceará, Caetano (2013) com trabalho nomeado: Impacto socioambiental dos fogões ecoeficientes na comunidade do km 60 do município de Limoeiro do Norte - CE, apresentado ao Departamento de Construção Civil do IFCE como Trabalho de Conclusão do Curso de Tecnologia em Saneamento Ambiental, apresentou como objetivo geral da investigação identificação dos impactos socioambientais após a implantação dos fogões ecoeficientes na do comunidade do KM 60, e como objetivos específicos verificar em que consiste o projeto dos fogões ecoeficientes; observar os benefícios de sua implantação e; identificar quais os procedimentos para a implementação do projeto em uma cidade.

O percurso metodológico consistiu no levantamento e análise bibliográfico, construindo e fortalecendo a base teórica da pesquisa, assim como a coleta dos dados da comunidade junto a amostra estabelecida, apresentando os resultados com base no trabalho de campo realizado em agosto/2012, com a colaboração dos alunos participantes no curso Gestão de Energia e Qualidade do Ar do PPGTGA.

Caetano (2013) verificou que apesar da implementação e manutenção a custos baixos dos

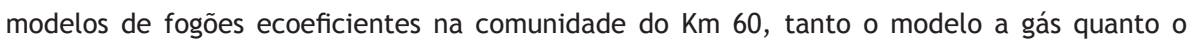
modelo tradicional a lenha ainda perduram em grande escala na região. Os efeitos benéficos para a saúde, segundo a autora, ainda não foram devidamente percebidos, pelo fato da fumaça ainda resistir com o novo modelo de fogão. Por residirem em uma região de clima semiárido, esse novo modelo não reduz de forma tão considerável a temperatura, sendo percebida por muitos como uma desvantagem.

A percepção dos usuários de fogão a lenha, eficiente e a gás butano, e seus reflexos na saúde humana, um estudo de caso na comunidade quilombola de Alto Alegre em Horizonte- CE, dos autores Fabrício, Rocha e Silva (2013) apresentado no Congresso Norte Nordeste de Pesquisa e Inovação (CONNEPI, 2013), analisa outro trabalho de campo executado pelo mesmo grupo de alunos do curso Gestão de Energia e Qualidade do Ar e que teve como objetivo identificar os agentes causadores de desconforto e agravos à saúde na Comunidade Quilombola de Alto Alegre, em Horizonte-CE.

A Comunidade Quilombola de Alto Alegre é localizada no distrito de Queimadas no município de Horizonte-CE e é composto por 375 famílias que ocupam uma área de cerca de 588,2774 hectares de terra. (MONTEIRO, 2009).

Assim, com a análise dos dados gerais da pesquisa realizada com os usuários de fogões a lenha tradicional e eficiente constatou-se que, apesar da maioria dos entrevistados dizer que não sente diferença em sua saúde quando utiliza o fogão eficiente conforme registrado na figura 1 , o uso desses altera de forma negativa a saúde dos entrevistados, principalmente a respiração e temperatura elevada do ambiente. 


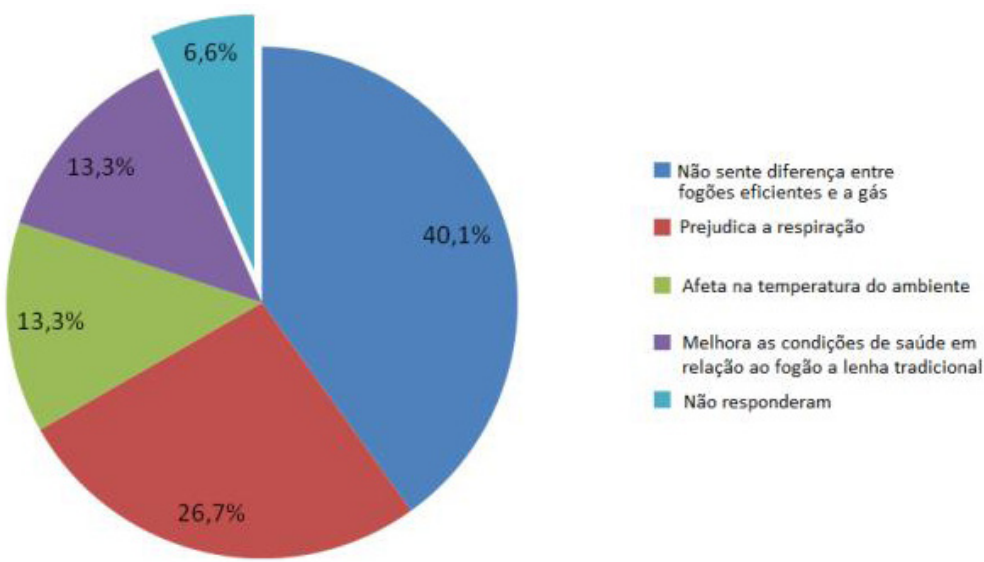

Figura 1. Percepção da Salubridade do Ambiente pelos Usuários dos Fogões Eficientes, Comunidade Quilombola Fonte: Fabrício, Rocha e Silva (2013)

\section{Conclusão}

A comunidade de baixa renda em estudo é um exemplo típico de um aglomerado populacional localizado numa região remota do Ceará, com acesso limitado a tecnologias modernas de produção descentralizada de energia, nomeadamente geradores GPL/diesel e sistemas de microgeração solar e/ou eólica que requerem elevado custo de investimento inicial. As comunidades encontram-se numa região com elevada disponibilidade de lenha do semiárido, onde a maioria dos moradores ainda utiliza fogões a lenha em simultâneo com fogões a gás butano.

Concluiu-se que, o fogão a gás butano é o preferido pelas comunidades em estudo, seguido do fogão ecoeficiente, sendo o primeiro o mais prático de operar, evitando o sobreaquecimento das casas, enquanto que o fogão a lenha ecoeficiente provoca o sobreaquecimento e a emissão de compostos poluentes para os espaços interiores, aquando do manuseio da madeira na câmara de combustão. Na maioria das habitações utilizam-se fogões ecoeficientes durante a maior parte do tempo, devido ao baixo custo de aquisição da lenha, reduzido consumo deste combustível e melhor confecção dos alimentos atribuindo um gosto especial à comida. 0 custo do gás butano é ainda elevado para comunidades de baixa renda.

\section{Bibliografia}

CAETANO, D. S. Impacto socioambiental dos fogões ecoeficientes na comunidade do $\mathrm{km} 60$ do município de Limoeiro do Norte - CE, Monografia- IFCE, Fortaleza-CE, 2013.

CARVALHO, R. L. Eficiência de fogões a biomassa e impactos na qualidade do ar interior. Dissertação (Tese de Mestrado em Sistemas Energéticos Sustentáveis), Universidade de Aveiro, Aveiro, 2010.

CARVALHO, R.L.T. SILVA, A. C. SANTOS, P.G.L. e TARELHO, A. L. C. Estudo compreensivo do conforto ambiental em habitações rurais do Ceará Revista GEONORTE, Edição Especial 2, V.2, N.5, Manaus, 2012

FABRÍCIO,T. N. R.; ROCHA N. N.; SILVAA. C. da. A percepção dos usuários de fogão a lenha, eficiente e a gás butano, e seus reflexos na saúde humana, um estudo de caso na comunidade quilombola de Alto Alegre em Horizonte- CE. Congresso Norte Nordeste de Pesquisa e Inovação, IFBA, Salvador-BA, 2013. 
INSTITUTO DE DESENVOLVIMENTO SUSTENTÁVEL E ENERGIAS RENOVÁVEIS. Fogões EcoEficientes, 2012. Disponível em: http://www.ider.org.br/projetos/fogoes-ecoeficientes. Acesso em 31 Agosto 2012.

MONTEIRO, F. H. P. Construção da identidade étnica entre os quilombolas de Alto Alegre. Dissertação (Mestrado em Sociologia - Departamento de Ciências Sociais) - Universidade Federal do Ceará, Fortaleza - CE, 2009

MAIA, G. et al. Implementation of a dissemination strategy for efficient cook stoves in northeast Brazil, Instituto de Desenvolvimento Sustentável e Energias Renováveis, 2008.

SIMON, L. G. et al. Win-win scenarios at the climate-development interface: Challenges and opportunities for stove replacement programs through carbon finance, Global Environmental Change, University of Colorado Denver, USA, 2011. 